\title{
A METAFUNÇÃO INTERPESSOAL NOS GÊNEROS RELATO E SENTENÇA: CONTRIBUIÇÕES LINGUÍS- TICAS PARA O ENSINO DE DIREITO
}

Tiago de Aguiar Rodrigues

Colégio Militar de Brasília

\section{RESUMO}

Este trabalho analisa a construção do sistema do modo oracional em textos dos gêneros relato e sentença, produzidos por estudantes do primeiro semestre do curso de Direito de uma faculdade particular de Brasília. O objetivo é discutir a importância da metafunção interpessoal para os estudantes compreenderem como a linguagem evidencia papéis sociais e identidades, em especial no âmbito do Direito. Para atingir esse objetivo, em um primeiro momento, justifica-se a escolha da Linguística Sistêmico-funcional (HALLIDAY \& MATTHIESSEN, 2014; FUZER \& CABRAL, 2010; NEVES, 2007; VIAN JR, 2009; e SILVA, 2010) como aporte teórico da pesquisa. Em seguida, definem-se o sistema MODO, bem como os elementos que o constituem (modo (finito + Sujeito) e resíduo (predicador + complemento + adjunto)), e se relaciona a discussão de modalidade a gêneros discursivos (SILVA, 2010). Na sequência, contextualiza-se o desenvolvimento da atividade de escrita em sala de aula e a constituição do corpus. Na seção de análise de resultados, cruzam-se as análises com os pressupostos teóricos. Os dados mostraram que os alunos, mesmo antes de terem explicações teóricas sobre os gêneros em questão, têm conhecimento prévio sobre as relações interpessoais nesses gêneros, principalmente na sentença, em que é possível definir melhor o actante principal: o juiz. Esses resultados comprovam a necessidade de se trabalhar, em sala de aula, aspectos léxico-gramaticais vinculados às condições de produção dos gêneros, bem como sugerem que a metafunção interpessoal pode ser um pontapé inicial para se discutir papéis sociais com estudantes que estão iniciando sua formação no ensino superior.

PALAVRAS-CHAVE: metafunção interpessoal; MODO; gêneros do discurso; ensino. 


\section{Introdução}

As pesquisas sobre gêneros discursivos têm fornecido uma rica contribuição para o ensino de língua desde pelo menos a década de 1990. Elas têm revelado como o foco do ensino em questões textuais contribui para que os estudantes compreendam a intrínseca relação entre as escolhas léxico-gramaticais e os papéis sociais desempenhados pelos autores dos textos, em diversos gêneros textuais. A Linguística Sistêmico-funcional (LSF) é uma das correntes teóricas que oferece relevantes contribuições para esse debate.

Assim, este trabalho analisa a construção do sistema do modo oracional (GOUVEIA, 2009) em textos dos gêneros relato e sentença, escritos por estudantes do primeiro semestre do curso de Direito de uma faculdade particular de Brasília. Discute-se a importância da metafunção interpessoal para que os estudantes compreendam como a linguagem evidencia papéis sociais e identidades, em especial no âmbito do Direito.

Para se atingir esse objetivo, o presente trabalho apresenta os pressupostos teóricos da LSF que norteiam a análise dos textos dos estudantes. Assim, discutem-se três aspectos da LSF que contribuem para uma visão dialética de linguagem (HALLIDAY e MATTHIESSEN, 2014; NEVES, 2007; FUZER e CABRAL, 2010; e SILVA, 2010). Em seguida, discutem-se as metafunções da linguagem: ideacional, interpessoal e textual. No restante da seção teórica, o foco recai sobre o sistema MODO e sobre os elementos que o constituem (modo (finito + Sujeito) e resíduo (predicador + complemento + adjunto)). Relaciona-se essa discussão de modalidade a gêneros discursivos (SILVA, 2010). Após a discussão teórica, apresenta-se a atividade de produção dos textos dos gêneros relato e sentença, num contexto de ensino de língua portuguesa para o curso de Direito. Depois, na seção de análise de resultados, cruzam-se os aspectos teóricos na análise dos textos dos estudantes.

Os dados mostraram que os alunos, mesmo antes das explicações teóricas sobre os gêneros, possuem conhecimento prévio acerca das relações interpessoais nesses gêneros, principalmente na sentença, em que é possível definir o actante principal, o juiz. Esses resultados comprovam a necessidade de se trabalhar, em sala de aula e de maneira sistemática, aspectos léxico-gramaticais vinculados às condições de produção dos gêneros.

Além disso, a experiência didática relatada nesta pesquisa sugere que a metafunção interpessoal pode ser o início das discussões sobre a 
representação social de um determinado profissional e os textos, inseridos em gêneros, que ele produz em contextos reais de uso.

\subsection{Pressupostos teóricos} aula?

1.1 Por que LSF para discussões de língua em sala de

Como o trabalho a ser desenvolvido nas aulas de língua portuguesa, independentemente do nível escolar, deve se basear em contextos reais, cabe ao professor selecionar um aporte teórico que conduza o aluno a um desempenho mais seguro nas atividades de interação linguística (NEVES, 2007). Nesse sentido, a LSF - por buscar nos textos as motivações de a língua variar em função das demandas de falantes nesses contextos reais (GOUVEIA, 2009) - é uma linha teórica coerente com essa perspectiva educacional.

De acordo com Silva (2010), há três aspectos da LSF que contribuem para uma visão dialética da linguagem, em que se mesclam os significados construídos discursivamente nos gêneros do discurso com os contextos. O primeiro é a capacidade de descrever funções e estruturas dos textos e de relacionar variáveis do contexto de situação à organização gramatical e semântica da linguagem. O segundo se relaciona ao fato de a LSF lançar um olhar descritivo para as estruturas dos gêneros, buscando entender a inter-relação entre eles. $O$ terceiro é o reconhecimento da importância de se buscar também os aspectos ideológicos presentes nos textos.

Halliday (1970, p. 142, citado em GOUVEIA, 2009) considera que o olhar do pesquisador em LSF recai não apenas no sistema da língua, mas também nas suas funções em simultâneo, haja vista que a forma particular que o sistema gramatical de uma língua assume está relacionada com as demandas sociais e pessoais a que a língua serve. Em outras palavras, essa abordagem procura entender como a língua se organiza enquanto sistema para produzir significados e, assim, atender a demandas sociais. Ao mesmo tempo, procura entender como essas demandas são refletidas nos usos linguísticos.

Assim, justifica-se olhar para o texto tanto como artefato (como significa o que significa e por que) quanto como espécime do sistema ("janela para o sistema"). Segundo Gouveia (2009, p. 19), o texto é espécime porque "suas descrição e análise servem o propósito de sabermos coisas sobre o sistema, a única forma de a este chegarmos, em termos 
de conhecimento descritivo". Como artefato, o texto se apresenta como unidade de análise e de descrição na LSF, na condição de modelo de análise textual. Obviamente, não se pode pensar que as análises são feitas de maneira individual, pois é por meio da produção de sentidos e discursos que se chega à organização do sistema linguístico, por onde se observa a organização da estrutura da língua para propiciar a produção de sentidos e discursos.

Assim, Fuzer e Cabral (2010) defendem que compreender a gramática de uma língua é o primeiro passo para se compreender a produção de sentido. Por meio da LSF, portanto, investiga-se a construção da experiência em termos semânticos e como tal experiência pode se manifestar em diferentes estratos da língua. Citando Droga \& Humphrey (2003), Fuzer e Cabral (2010, p. 13) consideram que o conhecimento da gramática permite ao falante "analisar e descrever os modos como as palavras são selecionadas, organizadas e sequenciadas dentro de um texto para produzir significados".

Nesse sentido, ao se trabalhar com texto em sala de aula, abordando-o tanto como fonte praticamente inesgotável de produção de sentidos e discursos quanto materialização dessa fonte em estrutura linguística, o professor poderá mostrar ao aluno que existe, por trás das regras gramaticais, motivação pragmática para a existência delas e que essa motivação também exerce força na forma como tais regras são constituídas. Ensinar língua portuguesa nesses moldes é, portanto, compreender a língua em uso, buscando explicações para o que o falante disse e como ele poderia ter dito, isto é, usar a língua para fazer escolhas "na envolvência de outras escolhas" (GOUVEIA, 2009, p. 22).

Martin, Matthiessen e Painter (2010, p. 2) defendem que esse estudo funcional da gramática também contribui para o ensino, pois apresenta habilidades que os alunos desenvolveram/precisam ainda desenvolver na escrita. Ao tomar consciência do sentido veiculado pela estrutura gramatical no texto, espera-se que o aluno reconheça rótulos como nome, verbo ou adjetivo atuando em funções como Ator, Processo, Meta etc. Nas palavras dos autores, esses rótulos tornam a análise gramatical semanticamente reveladora, mostrando como orações, grupos e frases do texto mapeiam significados. 


\subsection{Uma breve definição das metafunções da lingua-} gem

Antes de se tratar propriamente do sistema de modo, é necessário apresentar, ainda que de maneira resumida, quais são, segundo a LSF, as metafunções da linguagem e qual a importância delas para o estudo do texto.

Halliday \& Matthiessen (2014) sugerem que a linguagem tem duas funções básicas em relação ao ambiente social e ecológico do ser humano: produzir sentido para as experiências humanas e atuar nas relações sociais. Assim, o papel da linguagem seria construir a experiência humana, nomeando coisas e organizando-as em categorias, as quais variam conforme cada cultura. De maneira mais abrangente, a linguagem estabelece regras para a combinação desses elementos para organizá-los em relação ao tempo, às relações de causa-efeito etc., o que possibilita às pessoas relatarem suas experiências. Para que esses relatos produzam sentido, e consequentemente discursos, o falante lança mão de recursos lexicogramaticais para i) representar ações e atividades; ii) para trocar informações ou bens-e-serviços; e iii) para dar unidade funcional de valor textual à mensagem (GOUVEIA, 2009).

Cada um desses propósitos, subjacentes a todos os usos da língua, são denominados metafunções. Em i), está a metafunção ideacional, que se divide em duas subfunções: experiencial e lógica. Segundo Fuzer \& Cabral (2010), na subfunção experiencial, o falante constrói modelo de representação de mundo e tem como objeto de análise a oração. $\mathrm{Na}$ subfunção lógica, o falante combina grupos lexicais e oracionais, formando o complexo oracional. O objetivo de se analisar a oração sob viés da metafunção ideacional é interpretar o sistema de TRANSITIVIDADE, que molda a experiência em torno de processos, participantes e circunstâncias, trabalhando a oração como REPRESENTAÇÃO.

Em ii), está a metafunção interpessoal que, conforme Martin, Matthiessen e Painter (2010, p. 6), trata "o texto como um diálogo (mesmo se esse texto tiver um parceiro silencioso, como em um monólogo).” Essa metafunção revela o evento interativo em que o falante se encontra, qual papel discursivo ele assume para si e o que ele espera do seu interactante. A oração, então, é vista como TROCA.

Em iii), está a metafunção textual, cujo objetivo é investigar construção de mensagens por falantes para que participem de eventos de lin- 
guagem. Desse modo, segundo Silva (2010, p. 74), a oração se estrutura "para expressar significados textuais e transmitir uma mensagem por meio do sistema do Tema, que se constitui de dois elementos funcionais: Tema (ponto de partida da mensagem) e Rema (informação nova sobre o ponto de partida)".

De acordo com Gouveia (2009), o tema abriga, do ponto de vista ideacional, o primeiro elemento funcional, que pode ser participante, processo ou circunstância. O rema, por sua vez, traz informação relevante/ nova que será dada a respeito do tema. Do ponto de vista metatextual, portanto, a oração é compreendida como MENSAGEM.

Como o escopo deste trabalho é analisar o sistema de modo na produção dos gêneros relato e sentença, a próxima seção discute esse sistema. Definem-se os elementos que fazem parte da função interpessoal da linguagem e se reconhece que eles podem contribuir para a compreensão dos gêneros como construtores de valores interpessoais entre autor e leitor e entre participantes das cenas verbais.

\subsection{Sistema de modo: a metafunção interpessoal da linguagem}

A função interpessoal busca investigar como a linguagem subsidia o falante para ele interagir com outros membros da sociedade, estabelecendo papéis sociais e criando identidades. Pelos recursos disponíveis na língua, o falante se posiciona em relação àquilo que comunica e, assim, emite "avaliações sobre pessoas, objetos, entidades e todos os demais aspectos das relações sociais que negociamos em nosso dia a dia e que são passíveis de avaliação em suas várias escolhas" (VIAN JR, 2009, p. 100). Relações interpessoais implicam, portanto, tentativa, por parte do falante, de convencer e persuadir o outro a aceitar seu ponto de vista, bem como solicitar/fornecer a esse outro informações e bens-e-serviços.

Segundo Gouveia (2010), há dois tipos de papéis discursivos mais gerais que dão suporte a papéis mais específicos das relações interpessoais: dar e pedir. Logo, ou o falante está dando algo a seu interlocutor (informação, ordem etc.) ou está solicitando dele outra coisa. Obviamente, pelo fato de a linguagem estabelecer relação dialógica entre interactantes, existe entre dar e pedir "uma troca em que dar implica receber e pedir implica dar em resposta" (GOUVEIA, 2010, p. 34). 
Nessa troca, estão envolvidos dois tipos de commodities (HALLIDAY \& MATTHIESSEN, 2014): bens-e-serviços e informação. Bens-e-serviços utilizam a linguagem como meio para que atingir um propósito geralmente não linguístico - por exemplo, quando se solicita a alguém que feche a porta. Informação, por sua vez, utiliza a linguagem como meio e fim, pois o objetivo da interação é obter resposta verbal - por exemplo, quando se perguntam as horas a um desconhecido.

Para dar ou solicitar bens-e-serviços, o falante utiliza ofertas e ordens; para solicitar ou fornecer informações, utiliza afirmações e perguntas. Ofertas, ordens, afirmações e perguntas são as quatro funções discursivas básicas da função interpessoal (HALLIDAY \& MATTHIESSEN, 2014) e se materializam de maneiras distintas em orações. Nas trocas de informação, a função semântica é denominada "proposição"; nas trocas de bens-e-serviços, a função semântica é denominada "proposta" (SILVA, 2010).

Fuzer e Cabral (2010) sugerem recursos gramaticais utilizados para evidenciar a metafunção interpessoal da linguagem. São eles: marcadores de polaridade (sim, não, nada); advérbios de modo (provavelmente, possivelmente); marcadores atitudinais (infelizmente, felizmente, com prazer); modalidades (dever, poder, ter de, necessitar); marcadores avaliativos (interessante, necessário, prudente); e advérbios de frequência (usualmente, às vezes, raramente).

A metafunção interpessoal é realizada, no nível léxico-gramatical, pela parte da oração que desempenha o sistema de MODO, que realiza também proposições e propostas (FUZER e CABRAL, 2010).

O MODO fornece alternativas para que interactantes ajam: orações interrogativas, materializadas por meio de: 1) perguntas QU- ou de questões que podem ser respondidas com "sim" ou "não"; 2) orações declarativas (exclamativas e não exclamativas); e 3 ) orações imperativas, com verbo de ordem.

Dentro do MODO, há componentes oracionais que organizam como as quatro funções discursivas básicas da função interpessoal são introduzidas/ressignificadas no discurso. Esses componentes oracionais são assim denominados por Halliday e Matthiessen (2014): o modo, composto pelo sujeito e pelo finito; e o resíduo, composto por predicador (apenas um), complemento (até dois) e adjunto (até sete).

O modo fornece informação sobre o que está sendo discutido. Sua função precípua é apresentar a oração como evento interativo. Nesse sen- 
tido, ela conserva elementos estáveis representados por um sintagma nominal (na posição de sujeito) e elemento verbal que localize a ação em um tempo (finito). O modo, portanto, abriga a parte da oração que carrega a informação/pedido a ser debatido, propiciando movimentos interativos no diálogo, ou seja, indicando ao ouvinte/à plateia sobre qual assunto se está tratando.

O modo se estrutura mediante dois elementos com motivações semânticas distintas: sujeito e finito.

O sujeito, segundo Halliday e Matthiessen (2014), é a entidade sobre a qual se reivindica validade, isto é, a entidade capaz de realizar oferta ou comando. O sujeito é materializado na forma de sintagma nominal e, em língua portuguesa, pode ser omitido caso a desinência verbal consiga evidenciá-lo.

O finito, por sua vez, tem função de relacionar a sentença com o contexto no evento de fala. Em outras palavras, é por meio do finito que interactantes localizam o tempo de fala (presente, passado e futuro) em que ocorre a ação, bem como conseguem expressar/compreender o julgamento de valor presente na oração. À referência ao tempo de fala, dá-se o nome de tempo primário. À referência ao julgamento do falante, dá-se o nome de modalidade, que se divide em modalização e modulação - conceitos discutidos mais à frente.

Segundo Halliday e Matthiessen (2014, p. 144), tempo primário e modalidade contribuem para a criação da dêixis interpessoal, que é a localização da troca dentro do espaço semântico aberto entre falante e ouvinte. Essa localização implica considerar qualquer ato de fala contextualizado ao momento (presente, passado e futuro) em que o enunciado acontece, bem como o grau de (in)certeza da informação/expectativa e da validade do que é informado/esperado. Além da noção de "finitude", o finito também traz a noção de polaridade (escolha entre o positivo e negativo).

A segunda parte do MODO é o resíduo, o restante da oração. No resíduo estão o predicador, os complementos e os adjuntos. A presença de complementos e adjuntos dependerá da transitividade do verbo e das circunstâncias da ação verbal que se almeja transmitir.

O predicador está presente em quase todas as orações, à exceção daquelas em que há elipse, e é realizado por um grupo verbal, menos o operador modal/temporal, que funciona como finito no elemento modal. O predicador, segundo Halliday e Matthiessen (2014), tem as seguintes 
funções: i) especificar a referência temporal (tempo secundário); ii) especificar vários outros aspectos e fases, como parecer, tentar, acreditar; iii) especificar a voz ativa ou passiva; iv) especificar o processo (acional, evento, mental, relacional).

O complemento é o elemento realizado, em regra, por um grupo nominal ou por um grupo adjetivo (FUZER e CABRAL, 2010).

$\mathrm{O}$ adjunto, por sua vez, é o elemento normalmente realizado por grupo adverbial ou sintagma preposicional. Esse elemento não tem potencial para receber status interpessoal de responsabilidade modal, o que implica que o adjunto não pode ocupar a posição de sujeito. Dessa forma, $\mathrm{o}$ adjunto não pode construir argumentos ao seu redor (HALLIDAY e MATTHIESSEN, 2014).

\subsubsection{Polaridade e modalidade}

Como antecipado na seção anterior, o modo encerra duas noções caras à discussão da função interpessoal da linguagem: polaridade e finito.

A polaridade expõe a noção de afirmativo e negativo da oração "por um elemento finito, que pode ter uma forma positiva (é, foi, está, tem, pode) ou negativa (não é, não foi, não está, não tem, não pode). Orações interrogativas requerem informação relativa à polaridade, especialmente do tipo Sim/Não" (FUZER \& CABRAL, 2010, p. 118). Halliday \& Matthiessen (2014) defendem que a polaridade positiva e negativa é a mais provável de estar gramaticalizada em todas as línguas, geralmente a positiva como não marcada e a negativa como marcada.

A modalidade, por seu turno, materializa graus intermediários entre os polos positivo e negativo, construindo, pois, uma região de incerteza entre "sim" e "não". Silva (2010, p. 72) define dois tipos de modalidade, que assumem papéis distintos nas proposições e nas propostas: modalização, que se refere "à validade da informação apresentada em termos de probabilidade (possível/provável/certo) ou frequência (às vezes/frequentemente/sempre)"; e modulação, que é encontrada nas propostas (bens-e-serviços) e "diz respeito à confiança que o falante demonstra para ser bem sucedido na troca comunicativa. Na ordem refere-se ao grau de obrigação para a outra pessoa cumpri-la (...), e a oferta se refere ao grau de inclinação do falante para preenchê-la".

$\mathrm{Na}$ modalização, os recursos léxico-gramaticais mais comumente encontrados são verbos modais (pode, deve); adjuntos modais (possi- 
velmente, talvez, certamente, frequentemente, normalmente etc.); grupos adverbiais (sem dúvida, com certeza, às vezes, com frequência) e expressões como é possível, é provável, é certo, é costume (FUZER e CABRAL, 2010)).

Na modulação, os recursos léxico-gramaticais são verbos modalizadores (deve, deveria); adjuntos modais (necessariamente, obrigatoriamente, voluntariamente, alegremente); expressões como é necessário, é preciso, é esperado etc. (FUZER \& CABRAL, 2010).

\subsection{Um breve diálogo entre modalidade e gêneros do discurso}

Segundo Silva (2010), a modalidade evidencia variados graus e escalas de certeza, o que revela o nível de envolvimento do falante com a validade de uma proposição ou com a pressão exercida sobre o outro para que este cumpra ordem. Como a estrutura linguística se organiza de maneira específica dentro de cada contexto para atingir função social específica, fica claro que modalidade é marca importante no trabalho de reconhecimento e interação nos mais diversos gêneros discursivos.

Nas aulas de língua portuguesa, colocar em discussão a modalidade vinculada ao debate sobre gêneros contribui sobremaneira para "revelar a relação entre estruturas textuais e propósitos sociais, de modo a capacitar todos os estudantes a produzirem textos mais eficazes e críticos" (BAWARSHI e JO REIFF, 2013, p. 51). Ao visualizarem no texto do outro e utilizarem diferentes estratégias em seus próprios textos, os alunos conseguem relacionar as estruturas e as funções sociais, compreendendo que há relação dialética entre propósitos/motivos sociais e ações linguísticas exercidas pelos falantes.

Assim, o professor pode levar à aula diferentes gêneros do discurso e investigar, juntamente com os alunos, aspecto léxico-gramatical/ semântico/fonológico que torna um gênero específico para determinada situação comunicativa. Para Silva (2010), a combinação e mescla de gêneros, discursos e estilos em textos, evidenciada por traços semânticos, léxico-gramaticais e fonológicos, é fundamental para análise interdiscursiva de textos, a qual, por sua vez, se configura plano intermediário entre análises linguística e social.

No caso específico desta pesquisa, estabeleceu-se essa discussão entre os gêneros relato e sentença, amplamente debatidos no contexto profissional e acadêmico do Direito, ao qual pertencem os estudantes cujas produções textuais foram analisadas aqui. 
Com base na perspectiva da função interpessoal, a sentença possui como interactantes: o juiz, figura pública dotada do poder jurisdicional de julgar o caso; e o(s) autor(es), que levam a lide ao Poder Judiciário a fim de obter reparação pelo dano provocado pelo réu (SCHLEE e outros, 2012). Nesse sentido, na produção do gênero sentença, o aluno deve associar elementos modais que coloquem em evidência a capacidade decisória do juiz, bem como o posicionamento deste em relação a atos praticados pelo réu e sofridos pela vítima.

No caso do gênero relato, por se tratar de narrativa de cunho pessoal, a expectativa é que haja mais marcas descritivas das personagens envolvidas, com a opção de se estabelecer julgamento por parte do narrador em relação aos interactantes da história.

Por figurarem em contextos diferentes, a expectativa era que os alunos empregassem marcas modais que caracterizassem os gêneros, relacionando-os a contextos discursivos específicos.

\subsection{Contexto de produção do relato e da sentença} em sala de aula e seleção do corpus

A produção do relato e da sentença se deu na disciplina Língua Portuguesa, ministrada para uma turma de primeiro semestre do curso de Direito de uma faculdade particular de Brasília. Um dos objetivos da disciplina era debater questões atuais do universo jurídico, bem como refletir sobre o uso da linguagem em gêneros discursivos do Direito. Dessa forma, a disciplina pretendia evidenciar para os calouros do curso o modo como relações interpessoais eram criadas a partir desses gêneros.

Assim, optou-se por discutir com a turma o tema "crimes cibernéticos", tendo em vista o amplo debate desse tema na mídia e nos tribunais brasileiros, em especial após a sanção da Lei 12.737, de 30 de novembro de 2012, popularmente conhecida como "Lei Carolina Dieckman", que, entre outras medidas, tipifica criminalmente os delitos informáticos. A Lei recebeu esse nome em homenagem à atriz Carolina Dieckman, que, em maio de 2012, teve fotos íntimas divulgadas na Internet sem autorização.

Para motivação do debate, os estudantes primeiramente leram a notícia "Hackers postam fotos de Carolina Dieckmann nua no site da Cetesb" (G1 SP), na qual foram fornecidos detalhes sobre o caso. Na sequência, eles reconstituíram, em forma de relato, os fatos ocorridos no dia em que a atriz deixou o computador na loja até o momento da publicação 
indevida das fotos. Com base no relato, os colaboradores deveriam, na condição de juízes do caso, redigir a parte final da sentença, condenando ou absolvendo os réus.

Essa atividade foi desenvolvida logo no início do semestre. A proposta dela era, a partir das escolhas léxico-gramaticais das produções textuais, discutir o modo como relações, opiniões e atitudes são negociadas em gêneros do âmbito profissional do Direito - conhecimento ainda incipiente para quem está adentrando no ensino superior. No caso do relato, cuja finalidade é fazer com que o interlocutor conheça o que é enunciado, a expectativa era que os estudantes produzissem um texto com valores de informações. Na sentença, por sua vez, cuja finalidade é influenciar comportamentos, a expectativa era que os estudantes utilizassem valores de bens-e-serviços.

Cada estudante produziu, assim, um relato e uma sentença. Na turma havia 38 alunos, o que implicou a produção de 152 textos: 76 relatos e 76 sentenças. Já que todos os estudantes da turma eram recém-egressos do Ensino Médio, e, em tese, não haviam estudado ainda aspectos linguísticos e/ou jurídicos dos gêneros relato e sentença, foram selecionados aleatoriamente dois exemplares de cada gênero como corpus desta pesquisa. Esse corpus foi analisado com base nas categorias que compõem a metafunção interpessoal, conforme apresentado na seção anterior. Dados os limites deste artigo, não será apresentada a discussão que se seguiu ao debate coletivo sobre as escolhas léxico-gramaticais e o impacto delas na representação social dos operadores do Direito.

\subsection{Análises de dados}

Nesta seção, analisam-se, com base na metafunção interpessoal, os dois relatos e as duas sentenças que compõem o corpus. Para facilitar a leitura, apresentam-se, nas subseções 3.1 e 3.2, fragmentos dos relatos 1 e 2 , respectivamente, em negrito, e a análise logo abaixo; nas subseções 3.3 e 3.4, estão fragmentos das sentenças 1 e 2, respectivamente, em negrito, e a análise logo abaixo. Procurou-se manter os textos no original, sem correção.

\subsection{Relato 1}

(1) A atriz Carolina Dieckman deixou seu notebook (computador portátil) numa empresa de manutenção na manhã do dia 23 de abril de 2012. 
Nessa proposição, tem-se, no modo, o sintagma nominal "A atriz Carolina Dieckman" na posição de sujeito; deix-, como finito. No resíduo, -ou é o predicador; "seu notebook (computador portátil)", complemento; e "numa empresa de manutenção" e "na manhã do dia 23 de abril de 2012", adjuntos. A proposição indica troca de informação entre o autor do relato e o leitor, mas deixa implícita a existência de uma proposta (bens-e-serviços) entre o sujeito e a empresa de manutenção de computadores.

(2) A atriz teve seu notebook invadido por crackers, os quais pegaram fotos íntimas sem autorização da vítima.

Essa proposição mantém o sintagma "atriz" na posição de sujeito, agora beneficiário de ação de um interactante que até então era desconhecido: "crackers", adjunto dentro do resíduo. Houve, da proposição anterior para esta, quebra no fluxo das informações, pois o interactante "empresa de manutenção" é simplesmente silenciado. Na sequência, o autor aponta para proposição que informa o modo de agir dos crackers, que passam a ocupar a posição de sujeito.

(3) Daí em diante a atriz começou a receber e-mails dos crackers, os quais visavam o recebimento de 10 mil reais pagos por ela para não divulgarem as fotos íntimas da mesma.

Em (3), o autor acrescenta um adjunto de modo ("Daí em diante"), o que dá ao modo um significado associado à progressão temporal. $\mathrm{O}$ autor mantém o sintagma "A atriz" na posição de sujeito, indicando que esse é o tema do relato, e acrescenta ao finito a forma verbal "começou", que localiza o tempo de fala (primário) da ação expressa pelo predicador "receber". Este predicador recebe dois complementos ("e-mails" e "dos crackers"). "Crackers", novamente, é alçado à posição de sujeito que faz proposta de relação de bens-e-serviços com a vítima. Tal proposta é materializada no finito/predicador "visav-am" e no complemento desse predicador "o recebimento de 10 mil reais pagos por ela". O adjunto oracional "para não divulgarem as fotos íntimas da mesma" evidencia outra proposta dos crackers, neste caso com polaridade negativa, para não agirem.

(4) A atriz contatou conhecidos da área de segurança e a mesma foi orientada a colaborar, respondendo aos e-mails com intuito de obterem um flagrante, mas os crackers desistiram e acabaram por divulgar as fotos íntimas da atriz Carolina Dieckman.

Em (4), o sintagma "A atriz" volta a ocupar a posição de sujeito, e o autor insere na posição de complemento mais um interactante: "conhecidos da área de segurança". Destaca-se que ela solicitou informação a 
esse interactante, que, na troca de bens-e-serviços, propôs a ela colaborar agindo, respondendo aos e-mails. Novamente, há quebra na sequência dos fatos, pois é informado simplesmente que "Os crackers desistiram" e "acabaram por" (finito) "divulgar" (predicador) "as fotos íntimas da atriz" (complemento). Aqui, percebe-se determinação por parte dos crackers, o que demonstra um nível alto de inclinação.

\subsection{Relato 2}

(5) No dia 15 de maio de 2012, o site da Cetesb foi invadido por hackers, que colocaram fotos da atriz Carolina Dieckmann nua no lugar da página principal.

O Relato 2 se inicia com adjunto de modo ("No dia 15 de maio de 2012"), que contextualiza o momento em que houve invasão do "site da Cetesb" (sujeito) por "hackers" (adjunto). "Hackers" é, logo em seguida, alçado à posição de sujeito agente e há a identificação do outro interactante do gênero: a atriz Carolina Dieckman.

(6) O problema durou cerca de 10 minutos e, após isso, quem tentou acessar o site deparou-se com o site fora do ar.

Em (6), o autor mantém em destaque sujeitos não humanos e/ou indeterminados e coloca o elemento "site" em posição de complemento. O finito "tentou" denota a modalidade epistêmica de probabilidade, o que implica que a relação entre o sujeito "quem" e o predicador "acertar" se encontra em posição intermediária de modalização.

(7) Porém, a atriz recebeu e-mails dias antes exigindo 10 mil reais pela não publicação das fotos os quais a atriz respondeu que não pagaria por essa chantagem. (sic)

Em (7), o interactante "a atriz" passa a ocupar a posição de sujeito das orações que materializam duas proposições: uma informando o recebimento das mensagens (finito/predicador "recebeu") e outra da resposta dada pela atriz. Há também duas propostas: uma de polaridade positiva, na qual se exige o pagamento de dez mil reais; a outra, de polaridade negativa, da recusa da atriz em pagar a chantagem.

(8) Essas informações só chegaram ao conhecimento da polícia graças à colaboração de Carolina Dieckmann que procura os culpados para que a justiça seja feita.

No encerramento do relato, o autor evidencia a modalização presente em todo o gênero com o sintagma "Essas informações" na posição de sujeito. Além do sujeito, o modo traz ainda o adjunto modal "só", de 
probabilidade, e o finito "chegar", de ação no passado, em contraposição ao finito "procurar", no presente, o que indica que as ações ainda estão em curso.

\subsection{Sentença 1}

(9) Vistos e examinados os autos, consta no inquérito que Carolina Dieckmann foi vítima de um crime virtual.

A oração (9) materializa outro posicionamento em relação aos fatos: pelos predicadores "vistos", "examinados" e "foi", o autor atribui às cenas verbais modalidade epistêmica e alto grau de certeza. "Carolina Dieckman" aparece como sujeito novamente, mas agora em oração relacional em que é equiparada à "vítima".

(10) A denúncia foi recebida dia 15 de maio de 2012, o réu foi regularmente citado.

Em (10), também se nota nas cenas verbais modalidade epistêmica e alto grau de certeza, além da presença de adjunto de tempo. Na oração cujo predicador é "citado", destaca-se o uso do adjunto adverbial de modo "regularmente", que denota agora modulação da aceitação: era determinado que a citação fosse feita.

(11) Em alegações finais, sob forma de memoriais, o Ministério Público entendeu estar devidamente demonstrada a materialidade e autoria dos delitos, bem como a responsabilidade criminal do réu pugnando pela sua condenação, nos moldes da denúncia.

Em (11) aparece outro adjunto de modo, "devidamente", que reforça a modulação de obrigação: havia a necessidade de a materialidade, a autoria dos delitos e a responsabilidade criminal do réu serem comprovadas. $\mathrm{O}$ uso desse adjunto mostra a necessidade de, na sentença, o juiz se comprometer, mais do que no relato, com objetividade e veracidade dos fatos apresentados. Ademais, o emprego do predicador "pugnando" mostra a força do sujeito "Ministério Público" para embasar a tomada de decisão do juiz.

\subsection{Sentença 2}

(12) De acordo com os fatos apresentados pela acusação, a requerente foi lesada por ter seu computador invadido e seus documentos pessoais furtados e postas na internet, fato que, possivelmente, nunca será revertido.

Em (12), há presença de adjunto de modalização ("possivelmente") 
e de tempo ("nunca"). Novamente, por esses adjuntos, percebe-se a preocupação do "juiz" em tornar a cena verbal mais próxima da verdade e da forma como ele enxerga a relação entre sujeito ("fato"), finito ("será") e predicador ("revertido").

(13) Os réus maiores de idade, diante das suas ações que se caracterizam como desvio de caráter, terão de cumprir pena de reclusão em regime fechado de um ano e dois meses podendo evoluir para semiaberto.

O exemplo (13) evidencia a maneira de o juiz ser representado na metafunção interpessoal do gênero sentença. O uso do finito "terão de" e da oração reduzida "podendo" aponta para a prerrogativa de o magistrado impor, por modalidade deôntica, obrigações e permissões, respectivamente.

\subsection{Considerações finais}

A análise dos relatos e das sentenças mostraram a riqueza de se discutir o texto como objeto de análise da língua, tanto para o nível estrutural quanto para os sentidos e discursos que ela cria. Conclui-se que os estudantes, mesmo não tendo estudado aspectos léxico-gramaticais e discursivos dos gêneros propostos, têm conhecimento empírico acerca de como eles se estruturam. Pôde-se chegar a essa conclusão com base na análise de marcas da função interpessoal da linguagem, o que evidencia a importância de as aulas de língua terem como objeto de partida e chegada o texto, inserido em gêneros que fazem/farão parte da rotina profissional/ acadêmica dos estudantes.

Por um lado, esperava-se que, no relato, fossem apresentadas mais proposições, pois sua finalidade principal é a troca de informações. Contudo, por se relatar uma extorsão, os relatos trouxeram mais bens-e-serviços, com foco na chantagem dos hackers em relação à atriz. Ainda no relato, utilizou-se de poucos recursos da modalidade deôntica, priorizando a modalidade epistêmica, o que denota o conhecimento dos alunos de que o gênero relato não tem por finalidade obrigar o leitor do texto a tomar uma decisão, mas subsidiá-lo, no caso de o relato ser utilizado para embasar a sentença.

Por outro lado, como era esperado, a sentença lançou mão de ambas as modalidades, com maior destaque, no entanto, para a deôntica, o que demonstra a representação que os futuros operadores do direito têm da figura do magistrado: alguém que decide e vincula as decisões às 
atitudes que os envolvidos devem tomar. Como se observou na análise dos dados, na sentença, exatamente por empregar a modalidade deôntica, foram empregadas orações com valor de troca de bens-e-serviços.

Assim, esta pesquisa demonstra a importância de se trabalhar em sala de aula aspectos gramaticais relacionados à produção de sentido dos gêneros, bem como ao reconhecimento das metafunções propostas pela LSF. A partir da experiência relatada nesta pesquisa, sugere-se que a metafunção interpessoal seja o pontapé inicial para as discussões sobre a relação entre a representação social que se faz sobre um determinado profissional e os textos, inseridos em gêneros, que ele produz em contextos reais de uso.

Caso esse diálogo se estabeleça de maneira profícua no ensino, grandes são as chances de os alunos relacionarem os propósitos sociocomunicativos com as estruturas sociais, e estas com ações sociais e linguísticas situadas dentro do registro. 


\section{THE INTERPERSONAL METAFUNCTION IN THE REPORT AND SENTENCE GENRES: linguistic contributions to teaching law course}

\section{ABSTRACT}

This paper analyzes the construction of the mode system in texts of report and sentence genres, produced by first semester students of law in a private faculty in Brasilia. The aim is to discuss the importance of interpersonal metafunction so that students understand how language shows social roles and identities, especially in the field of Law. To reach this goal, the choice of Systemic-Functional Linguistics (HALLIDAY \& MATTHIESSEN, 2014; FUZER \& CABRAL, 2010; NEVES, 2007; VIAN JR, 2009 and SILVA, 2010) as the theoretical framework adopted in this research is justified. Then, according to this theory, the MODE system is defined, as well as the elements that constitute it (mode (finite + Subject) and residue (preacher + complement + adjunct)), and the discussion of modality is related to discursive genres (SILVA, 2010). In sequence, the development of the activity of writing in the classroom is contextualized, as well as the formation of the corpus. For the analysis of the results, these are crossed with the theoretical assumptions previously presented. The data showed that students, even before having theoretical explanations about the genres in question, have prior knowledge about interpersonal relations in these genres, especially in the sentence, where it is possible to better define the main actant: the judge. These results confirm the need to explore lexical-grammatical aspects linked to the production conditions of the genres in the classroom, as well as they suggest that the interpersonal metafunction can be a kick-start to discuss social roles with students who are starting their studies in higher education.

KEYWORDS: interpersonal metafunction; MODE; discourse genres; education. 


\section{REFERÊNCIAS}

BAWARSHI, A. S. \& JO REIFF, M. Gênero: história, teoria, pesquisa e ensino. São Paulo: Parábola Editorial, 2013.

G1 SP. Hackers postam fotos de Carolina Dieckmann nua no site da Cetesb. G1, 2012. Disponível em <http:/g1.globo.com/sao-paulo/noticia/2012/05/ hackers-postam-fotos-de-carolina-dieckmann-nua-em-site-da-cetesb.html $>$. Acesso em 13/5/2018.

GOUVEIA, C. A. M. Texto e gramática: um introdução à linguística sistémico-funcional. Matraga, Rio de Janeiro, v.16, n.24, jan./jun. 2009 (p. 13-47).

FUZER, C. e CABRAL S. R. S. Introdução à gramática sistêmico-funcional em língua portuguesa. Santa Maria: Universidade Federal de Santa Maria, 2010. HALLIDAY, M.A.K. e MATTHIESSEN, C.M.I.M. An introduction to functional grammar. 4a. ed., Oxford, Londres: Arnold, 2014.

MARTIN, J. R., MATTHIESSEN, C. M. I. e PAINTER, C. Deploying Functional Grammar. Londres: Commercial Press, 2010

NEVES, M. H. M. Texto e gramática. São Paulo: Editora Contexto, 2007.

SCHLEE, M. B. e outros. A linguística sistêmico-funcional no quadro das grandes teorias linguísticas: propostas de aplicação. Anais do XVI CNLF. Rio de Janeiro: CiFEFiL, 2012 (p. 2026-2110).

SILVA, E. C. M. Do discurso à gramática: um enfoque crítico e funcional de gêneros. Cadernos de Linguagem e Sociedade, 11 (2), 2010 (p. 62-77).

VIAN JR., O. O sistema de avaliatividade e os recursos para a gradação em Língua Portuguesa: questões terminológicas e de instanciação. D.E.L.T.A., 25:1, 2009 (p. 99-129).

Recebido: 09/10/2017

Aceito: 10/06/2018 